\title{
A spatiotemporal appraisal of road traffic accident in Kaduna metropolis, Nigeria
}

\author{
Abdulkadir Muhammed Yahaya ${ }^{1 *}$, Abdullahi Sani Yusuf ${ }^{2}$, Inusa Musa ${ }^{3}$, Fatima Ilyasu Maaji ${ }^{4}$, \\ Suleiman Umar Bambale ${ }^{5}$, Rowland Oscar ${ }^{6}$, Abubakar Muhammad Bawa ${ }^{7}$, Angela \\ Uwanuakwa $^{8}$ \\ Department of Geography, Kaduna State University, Kaduna, Nigeria ${ }^{1 *}$ \\ Department of Geography, Ahmadu Bello University, Zaria, Nigeria ${ }^{2}$ \\ Department of Geography, Federal College of Education, Zaria, Nigeria ${ }^{3,4,5,6,7,8}$ \\ abdulkadirmuhammed2@gmail.com ${ }^{1 *}$, abdullahisaniyusuf@gmail.com ${ }^{2}$, inusaecole@ @mail.com ${ }^{3}$, \\ antyfati2016@gmail.com ${ }^{4}$, talk2usbambale@gmail.com ${ }^{5}$, oscarrowland2013@gmail.com $^{6}$, \\ abubakarmuhammadbawa28@gmail.com ${ }^{7}$, angelauwanu@gmail.com ${ }^{8}$
}

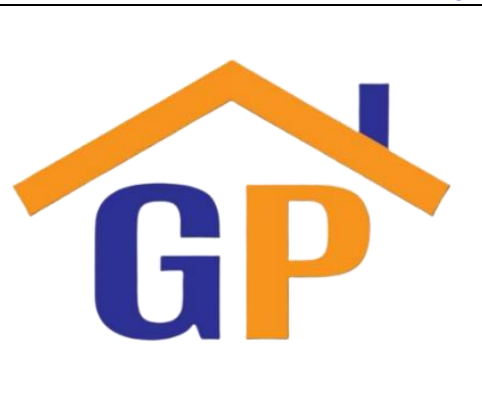

Article History

Received on 12 April 2021

Revised on 17 April 2021

Accepted on 7 May 2021

\begin{abstract}
Purpose: Road accident has been claiming lives and no amount of research will be enough to expose the causes and dangers. This study appraises the causes and analyses the variation of road accidents in the Kaduna metropolis, intending to reduce it.
\end{abstract}

Research methodology: The data used was obtained from Federal Road Safety Corps and complemented by the researchers' field survey. Eight members of the research team went to the 24 bus stops identified each month rotationally. Both descriptive and inferential statistics were applied in the analysis.

Results: There was a high correlation of mortality and road accident injuries as confirmed by $\mathrm{r}$-value 0.7 using pearson product moment correlation. Accidents occur most in the morning and afternoon and the season with most accident occurrence was the dry season. The combination of over speeding and other factors were the major causes of road accidents.

Limitations: The study used data published in 2016, although a follow-up data verification was conducted in 2017 and 2018. Therefore, the study is old and the results might have changed and might not necessarily be reliable.

Contribution: Road accidents hot spots areas, causes, and patterns were exposed to guide the road users in order to avoid the accident. The study can also be replicated in other study areas with similar characteristics.

Keywords: Geographical, Mortality, Road traffic accident, Kaduna metropolis

How to cite: Muhammed, A. Y., Sani, A. Y., Musa, I., Ilyasu, F. M., Suleiman, U. B., Oscar, R., Muhammad, A. B., \& Uwanuakwa, A. (2021). A spatiotemporal appraisal of road traffic accident in Kaduna metropolis, Nigeria. Journal of Social, Humanity, and Education, 1(3), 209-226.

\section{Introduction}

Whenever there is a collision between vehicles, pedestrian, animal, geographical or architectural objects, it is said to be a road accident. For a road accident to occur, there must be a moving vehicle (Ohakwe, Iwuse, Chikezie, 2011). Also, Astrom, Kent and Jovi (2006) see road traffic accident when there is a collision between a moving vehicle and a moving or a stationary object that result in property damage, personal injury or death. Accidents may be fatal, resulting in death of road users (passengers, drivers or pedestrians), serious if passengers sustain injuries of various degrees or minor when it is not severe enough to cause substantial hardship or when there is no injury but only bruise of vehicle. Sheriff (2009) found that drivers mostly undergo a change in behaviour when behind the 
wheel of a car in most cases. They take aggressive nature without due regard to other road users. The study also found out that anxiety is to be found in the low age group. This group has high accident records given the increasing toll in terms of deaths and injuries from road accidents. Several studies have been initiated to study road traffic accidents.

Every year, more than a million people die because of road traffic accidents. Youths aged 15-29 get injured through accidents, killing them many times because of road traffic accidents. Although the low and middle-income earner countries are just about half of the world's vehicles owners, $91 \%$ of the world's accident victims are from there. The pedestrians, cyclists, motorcyclists and other vulnerable groups account for half of the victims. Unless something is done, accidents might kill about two million people from 2020 each year. Few countries that account for about $7 \%$ have laws enough to address five risk factors that cause an accident: speed, drink-driving, helmets, seatbelts, and child restraints (WHO, 2013).

Previous studies have also shown that human negligence was the main cause of road accidents (Onakoimaya, 1981). There are many forms of negligence and these factors include carelessness, drunkenness and recklessness of the driver, among others. Crack and potholes also cause accidents (Agbonkhese, Yisa, Daudu, 2013). There is also the issue of mechanical malfunction resulting from the carelessness of the vehicle owners to do the proper check and service. Most of the road accidents are unexpected. When oil was discovered, it came with a lot of negative consequences. Before the discovery of oil in commercial quantity, accidents were insignificant. Oil discovery enriched many people which increased vehicle ownership and this, in turn, increased vehicle accidents. Additionally, the oil boom was used to build many roads that were not up to standard, causing road accidents that claim the lives of many Nigerians (Sheriff, 2009).

A report from Federal Road Safety Corps [FRSC] (2015) had shown that Kaduna State had the highest road traffic accident in Nigeria and Nigeria had the highest in Africa. Kaduna metropolis covering over $131 \mathrm{~km}^{2}$, was one of the areas with a high record of road traffic accidents. The FRSC Kaduna State command also reported in 2015 that 463 road traffic accidents were recorded in Kaduna State. This figure is alarming and calls for investigation of the causes because more roads with standards have been built but to no avail, hence the initiation of this study.

\section{Objectives of the study}

i. Identify the causes and spatial variation of road accidents in the study area

ii. Appraise the trend and pattern of road traffic accident occurred in the study area

\section{Literature review}

In this section, the concepts to be reviewed are the Haddon matrix, the systems approach to road safety and Geographical Information System (GIS). The Haddon matrix uses periods in relation to other factors to discuss accidents. Additionally, Haddon matrix identifies the interaction between road users, the roads where vehicles ply on the vehicles as interventionists for safety.

\subsection{The Haddon Matrix}

The matrix gives a significant update and distribution of traffic-related interventions. Haddon matrix advised that, three periods should be considered when dealing with traffic accidents. They are: (before-crash, during crash and after-crash) against four types of factors (human, vehicle, environmental and social). The Global Plan for the Decade of Action for Road Safety 2011-2020 promotes this integrated approach (Eshbaugh, 2012).

Table 1. Haddon Matrix

\begin{tabular}{|c|c|c|c|c|c|}
\hline & Pre-crash & & Crash & & Post-crash \\
\hline Human Factors & $\begin{array}{l}\text { Licensing, } \\
\text { driver } \\
\text { impairment, } \\
\text { distractions. }\end{array}$ & $\begin{array}{l}\text { training, } \\
\text { attitude, }\end{array}$ & $\begin{array}{l}\text { Personal } \\
\text { equipment. }\end{array}$ & protective & $\begin{array}{l}\text { Crash reaction, } \\
\text { education/training } \\
\text { evaluation. }\end{array}$ \\
\hline
\end{tabular}




\begin{tabular}{|c|c|c|c|}
\hline Vehicle factors & $\begin{array}{l}\text { Braking, vehicle } \\
\text { design, maintenance, } \\
\text { passenger/loads, } \\
\text { safety equipment. }\end{array}$ & $\begin{array}{l}\text { Vehicle safety } \\
\text { equipment, personal } \\
\text { safety equipment (i.e. } \\
\text { seatbelts use) }\end{array}$ & $\begin{array}{l}\text { Automatic collision } \\
\text { notification } \\
\text { crash research. }\end{array}$ \\
\hline Environmental factors & $\begin{array}{l}\text { Regulation, } \\
\text { enforcement, harzards, } \\
\text { natural hazards, driver }\end{array}$ & $\begin{array}{l}\text { Other vehicle design, } \\
\text { road furniture. }\end{array}$ & $\begin{array}{l}\text { Emergency medical } \\
\text { service response, } \\
\text { health infrastructure. }\end{array}$ \\
\hline & $\begin{array}{lr}\text { distractions, } & \text { built } \\
\text { environment, road } & \text { resign/maintenance. }\end{array}$ & & \\
\hline Social factors & $\begin{array}{l}\text { Enforcement, } \\
\text { awareness, insurance } \\
\text { incentives, rider peer } \\
\text { pressure. }\end{array}$ & $\begin{array}{l}\text { Safety community } \\
\text { attitude/involvement. }\end{array}$ & $\begin{array}{l}\text { medical community } \\
\text { attitude/involvement, } \\
\text { political will }\end{array}$ \\
\hline
\end{tabular}

The Haddon Matrix makes the categorization of road accidents by phase of the crash to be simpler to analyze. This categorization allows for an immediate detailed knowledge about the severity, type of collision, cause of the accident and what happens before and after the accident. These phases give a clear view and make it relatively simpler for a person who wishes to study accidents based on these categorizations.

\subsubsection{Before-crash phase}

Several factors cause crash including drug abuse, taking alcohol before driving, poor vision, aggressiveness, bad driving habits, riding vehicles in poor conditions, poor road networks are some of the factors considered that increase the possibility of road accidents. Accident prevention and avoidance are discussed here (Eshbaugh, 2012).

\subsubsection{Crash phase}

Whenever there is an accident, there could be damages to the vehicles, infrastructure, and different form of human injuries. Factors that contributed to this might be potholes, vehicles themselves that are in bad shape and others. When the crash occurs, a fire outbreak could damage the vehicle, occupants, or even pedestrians. Passenger's or commuter's safety is of importance at this stage. Thus, the vehicle should be designed so that they should provide preventing and safety gadgets in the event of crashes to reduce or expel shock.

\subsubsection{The post-crash phase}

This is the final phase after the accident must have occurred. It deals with saving lives, reduction of injuries and disabilities and prevention of unnecessary deaths. The the aim is to provide a prompts emergency assistance using communication and transportation as well as the provision of medical assistance. There must be vehicle for evacuation of the road accident victims for the survivors. Allowing hospital staff access to attend to victims without police reports. (Eshbaugh, 2012).

\subsection{The safe system approach to road safety}

This approach, like the Haddon Matrix, is holistic in nature but somehow different. It examines guides and enhances safe journeys. The main aim of a safe system approach is to ensure that road users are responsible so that risk can be reduced to ensure safety of road designers, maintenance, pedestrians, commuters, and all those who use the road transport system. This system approach understands the nature of human being that is highly susceptible to injury and human being often makes mistakes. The human attitude is not independent of the human population plying the roads and their perception of what risks are and is encountered (WHO, 2003). For instance, many road users wrongly interpret road signs and symbols or make poorly using road facilities. Thus, the safe system approach to road safety does not ignore the risk-taking behavior of human being, but rather, recognizes it and gives a considerable allowance for human error. Therefore, a safer road traffic system promotes, 
accommodates and compensates for human error and fallibility. The system accounts for human vulnerability using the following principles:

1. The limits of human performance: that we humans all make mistakes and we need to accept the fact we make them and try to reduce or adjust them as much as possible.

2 . The physical limits of human tolerance to violent forces; we are physically and mentally vulnerable and susceptible to a traffic crash.

3. Shared responsibility: we should all be responsible for keeping road safe. It is not an individual role, but everybody's responsibility.

4. A forgiving road system: so that whenever there is a road crash, death and injuries can be avoided or minimized.

According to WHO (2009) report on a comprehensive approach to road safety, there must be an identification of interactions between the vehicle, the environment, and the road users for any meaningful and effective intervention. Adopting this too is not individual work but requires the involvement of interest groups on road safety to collaborate and enhance security. The following are areas of collaboration of these interest groups:

1. Safe roads and roadsides that are predictable and forgiving of mistakes. The designers of roads should make them encourage road users to behave rationally when using roads.

2. Safe speeds that suit the function and level of safety of the road. Road users should exceed the design road speed when driving or using roads.

3. Safe vehicles that help prevent crashes and protect road users from crash forces that cause death and serious injury. Manufactures of vehicles should not compromise safety and standard in their designs.

4. Safe road use is the one that makes sure that only skillful, competent and people who obey road and traffic regulations ply or use roads. This is the responsibility of enforcers of road rules and regulations to observe and improve safety. Police warders, Road Safety Corps and a host of others would play a big role here (New Zealand Transport Agency, 2013).

Those many strategies have been implemented, but still road crash occurs. However, the essential strategy to the safe system approach is to ensure that the impact energies remain below the threshold likely to produce either death or severe injury. This threshold will vary from crash scenario to crash scenario, depending upon the level of protection offered to the road users involved.

\subsection{Geographical Information System (GIS)}

Geographical Information Systems (GIS) are computer-based systems that enable users to collect, store, process, analyze and present spatial data (David, 2003). It provides an electronic representation of information, called spatial data, about the Earth's natural and man-made features. A GIS references these real-world spatial data elements to a coordinate system. These features can be separated into different layers. A GIS system categorizes information in layer form for easy maintenance, analysis and visualization. For instance, layers can represent environmental issues like roads constructions and designs, soil erosion, flooding, and so on. Zoological issues like wildlife habitat. Climatic issues like weather forecasting. Different applications create and use different layers. A GIS can also store attribute data, which is descriptive information of the map features. This attribute information is placed in a database that gives more insight about spatial data. A GIS allows the examination of both spatial and attributes data at the same time. Also, a GIS lets users search the attribute data and relate it to the spatial data. Therefore, a GIS can combine geographic and other types of data to generate maps and reports, enabling users to collect, manage, and interpret location-based information in a planned and systematic way.

GIS systems are dynamic and permit rapid updating, analysis, and display. They use data from many diverse sources such as satellite imagery, aerial photos, maps, ground surveys, and global positioning systems (GPS). GIS represents a new paradigm shift for the organization of the information and the design of information system, the essential aspect of the use of concept of location as the basis of structuring information systems. Traffic accident analysis means investigating the causes of 
accidents, determining hazardous locations (Accident Prone Locations), and determining to enhance road features to evaluate traffic safety and enhancement. GIS can easily represent accident and road accident based results using various tools like linear referencing, dynamic segmentation, and spatial analyst (Deepthi and Ganeshkumar 2010). Moreover, query can be easily performed, enhanced by graphical representation. Road characteristics, demographic and socio-economic data to enhance highway safety analysis can also be integrated into the study.

\subsection{Accident database and GIS}

GIS permits users to display database information geographically. It can also provide a common link between two or more previously unrelated databases. The most helpful aspect of GIS as a management tool is its ability to associate spatial objects (street names, milepost, route number, etc.) with attribute information (accidents, cause, etc.). Most of the documents reviewed consider using GIS in transportation under either for general data maintenance (primarily inventory of transportationrelated incidents) or simple data analysis.

A study conducted by Agbonkese, Yisa and Akanbi (2013) sees an accident as when a vehicle suddenly collides with another vehicle, pedestrians, animals, road debris, or other stationary obstructions such as tree or utility pole. Since road traffic accidents will rarely give warning, reckless drivers should anticipate their recklessness. It can also be caused by a single factor or by a combination of these factors.

In the study, they categorized the causes of road traffic accident into:

1) Vehicle operator or driver factor.

2) Vehicle factor.

3) Road pavement condition factor.

4) Environmental factors.

\subsubsection{Vehicle operator or driver factor.}

This centers all the cause on the shoulders of drives because they control the vehicles not the commuters and other road users. In Nigeria, studies have found that about $57 \%$ of road accidents are caused by drivers alone, while drivers in relation to other factors cause about $93 \%$. (Agbonkhese, Yisa and Akanbi, 2013).

Many drivers on Nigeria roads do some of these:

1) Speed and indiscriminate use of sirens.

2) Drinking-driving and use of drugs.

3) Distracted driving.

4) Inexperience and unqualified drivers.

5) Nonuse of safety device and negligence of duty by government established agencies.

\subsubsection{Speed and indiscriminate use of sirens}

Many drivers indulge in over speeding, thereby cause avoidable crashes. Some drivers, especially learners are also guilty of travelling below the standard speed. This one cause accident too. There is also the issue of indiscriminate use of sirens that frighten many road users and lead them to crash with avoidable objects. Politicians and top government officials are guilty of this and bullying vans that take money to banks.

\subsubsection{Drinking-driving and the use of drugs}

Many drivers indulge in drinking-driving, increasing both the risk of traffic accidents and the likelihood that death or severe injury will result. The risk of being involved in a traffic accident rises significantly above a Blood Alcohol Concentration (BAC) of $0.04 \mathrm{~g} / \mathrm{dl}$. Doctors often advise patients to abstain from driving vehicles or operating machines while under certain drugs as these drugs are known to cause side effects of sleepiness and fatigue, leading to possible accident occurrence, but many have not complied (Agbonkhese, Yisa and Akanbi, 2013). 


\subsubsection{Distracted driving}

Many types of distractions can cause or lead to impaired driving, but recently there has been a marked increase worldwide in the use of mobile phones by drivers that is becoming a growing concern for road safety. The distractions caused by mobile phones can impair driving performance in a number of ways. E.g. longer reaction time (notably braking reaction times, but also reacting to traffic signal) impaired ability to keep in the performance with young drivers at particular risk of the effect of distractions resulting from this use. This is to say that drivers using mobile phones are likely to be involved in a road traffic accident than those who do not use mobile phones. Although hands-free phones are much safer than hand-held phone sets, many drivers who use phones while driving do not have them, thereby increasing the chances of road accidents or crashes.

\subsubsection{Inexperienced and unqualified drivers}

The majority of Nigerian drivers do not possess the proper authorization from government authorities, like the Federal Road Safety Corps (FRSC) and are unqualified before driving cars on the road pavements. Drivers go anyhow without learning the basics of road traffic regulations. They put their lives and that of other road users at risk of traffic accidents (Agbonkhese, Yisa and Akanbi, 2013). As a result of their inexperience, since they were never given any tutorial or taught how to use their vehicles on a highway by government accredited driving schools, their decision-making ability and reaction speed to traffic is terrible (Agbonkhese, Yisa, and Akanbi, 2013).

\subsubsection{Nonuse of safety device and negligence of duty by the government established agencies}

Many Nigerian drivers do not put their seat belts and seat belts as essential safety devices that protect drivers from suffering in road accidents. The use of vehicle seat belts also helps to ensure that the driver is in an upright and comfortable position, thus enabling the driver to operate the vehicle properly. However, this provided safety device had been grossly abused thus, increasing the risk of fatalities among front-seat and rear-seat passengers. Also, most motorcyclists or their passengers do not wear helmets while driving; thus, they are exposing themselves and other road users to road traffic accidents (Agbonkhese, Yisa, and Akanbi, 2013).

Officials of government agencies such as the Federal Road Safety Corps (FRSC), Kaduna State Traffic Law and Enforcement Agency (KASTLEA), do not help matters as they have been seen to take their duties for granted by just being mere spectators each time they came across a driver or a passenger not wearing a seatbelt, a driver using mobile phones or a motorcyclist not wearing a helmet. When they act sometimes, they only do to collect bribe.

\subsubsection{Vehicle related factor}

The vehicle is also an important factor in causing accidents in Nigeria. Many vehicles without a functional horn, side mirrors, wipers, braking system, trafficators, headlights, and brake lights (to mention just a few) are found. Malfunctioning of any vehicle part such as tires, engine, braking system, light system can cause a road traffic accident. The vehicle's reliability is itself a function of the vehicle's condition at every given time. Vehicle components and vehicle maintenance are the two main components that affect vehicle factors related to causes of road traffic accidents.

\subsubsection{Road pavement condition factor.}

Until recently that some politicians intervene in states like Kaduna to provide standard roads, many Nigerian roads are arguable one of the worst in road accident in the world, because they are often poorly designed necessary essential road facilities like drains are not adequately provided for and they are rarely rehabilitated and are in dilapidated states. The deplorable conditions of the highways create a scenario that makes vehicles and other road users' susceptible to a road traffic accidents. This shows that road traffic accidents are not only caused by human factor or vehicle factor but also road pavement condition factor. (Agbonkhese, Yisa and Akanbi, 2013)

\subsubsection{Environmental factor}

The environmental-related condition has to do with the weather condition of places. Sometimes the weather could be foggy, sunrays, misty and/or with torrential rain, which is not suitable for a journey, 
but many drivers ignore these environmental condition signs, thereby exposing their lives and the lives of others to a road traffic accident.

The above-listed factors can be classified as the causes of their impressionable influence on road traffic accidents. In research by Salihu (2007), also categorize the causes of road traffic accident synonymously to that of Agbonkhese, Yisa and Akanbi (2013), where they classified the causes into:

i) Driver related factor.

ii) Road related factor.

iii) Environmental related factor.

Here we can see that in both types of research, the categorization of the causes of road traffic accidents is relatively the same. In general, these factors are the causes of road traffic accidents, but the severity of the accident strongly depends on the degree to which these factors have been violated. In addition, Salihu (2007) tries to highlight the spatial and temporal trend in road traffic accidents in the Zaria Local Government Area of Kaduna State. The study listed the causes of road traffic accident occurrence and also categorized road traffic accident into;

a) By degree of severity: That is accidents into fatal, severe and minor injuries. This categorization allows for the computation of various accidents induced, for example.

i) Severity index

ii) Fatality index

iii) Non-severity index

iv) Casualty index

b) By type of collision: These allow for the categorization of accidents by their mode of collision, which include;

i) Nose tail collision

ii) Side collision

iii) Hit on pedestrian, animal, or an obstacle.

c) By cause of the accident: As discussed earlier, the causes of road traffic accident where categorized into:

i) Vehicle operator or driver factor

ii) Vehicle factor

iii) Road pavement condition factor

iv) Environmental factor.

These were notably considered to be the causes of road traffic accidents by many researchers.

d) By phase of the crash: they followed the Haddon Matrix (1969) classification where he classified accidents on roads into;

i) Before-crash phase.

ii) During-crash phase.

iii) After-crash phase.

Using the Haddon Matrix, the phases were categorized into; human vehicle and physical environment. In addition, Salihu (2007) presented detailed data spanning the period of 2003 to 2005 based on the above categorization. He clearly showed that even though the number of accidents, in general, was decreasing, the fatality rate and injury index had increased. However, it could appear that for a given state, as population increase and some vehicles increase, the number of accident fatalities per annum will increase.

Lives lost through road traffic accidents are many, with a total of about 14,300 deaths from 2003 to 2005. The highest number of fatalities was recorded in 2005 when about 5,200 people lost their lives through road traffic accidents $\underline{(\mathrm{Salihu}, 2007)}$. In a report by $\underline{\mathrm{FRSC}(2012)}$, a worrying finding was 
reported between 2000 to 2011; there has been a rapid fluctuation of death through road traffic accident where 5,700 people lost their lives in 2002 and in 2001, 6,000 people lost their lives through road accident. That was how the incidence continued until 2006 where about 6,700 people lost their lives in a road accident and it had been marked as the year with the highest toll of fatalities.

An earlier study by Oduguru (1992) reported that from 1981 to 1983, Nigeria recorded unprecedented figures. This was as a result of increased income by many families to own vehicles. The assertion that the death toll resulting from a road accident is high and is further shown when the average number of deaths per total accident for all years leads to about 14 to 13 dying each day since 1975 after the oil boom. For any given country, holding the number of vehicles constant, an increase in population is matched by the rise in road accidents as more people travel, more pedestrians come into conflict with vehicles, and more accidents are expected to occur (Salihu, 2007). As stated earlier, about 1.24 million people die each year as a result of road traffic accident world-wide (WHO, 2013). This incidence is more severe in developing countries. Nigeria in Africa has the highest number of death per 10,000 people each year and the victims are mostly in the middle age group (15-29 years). This accident prevalence is more drastic in Kaduna state (FRSC report, 2012).

\section{Study area and methodology}

\subsection{Study locations}

Kaduna metropolis is located in the North-Western part of Nigeria between the Latitudes $10^{\circ} .21^{12} 3^{11} \mathrm{~N}-10^{\circ} .52^{1} 30^{11} \mathrm{~N}$ and Longitudes $7^{\circ} .23^{1} 25^{11} \mathrm{E}-7^{\circ} .44^{12} 28^{11} \mathrm{E}$. It covers an area of $131 \mathrm{~km}^{2}$. This includes the whole of Kaduna-North Local Government Area, Kaduna-South Local Government Area, and parts of Igabi local Government Area and Chikun Local Government Area (The Forum of Cities in Transition, 2016). See Figure 1 and Figure 2.

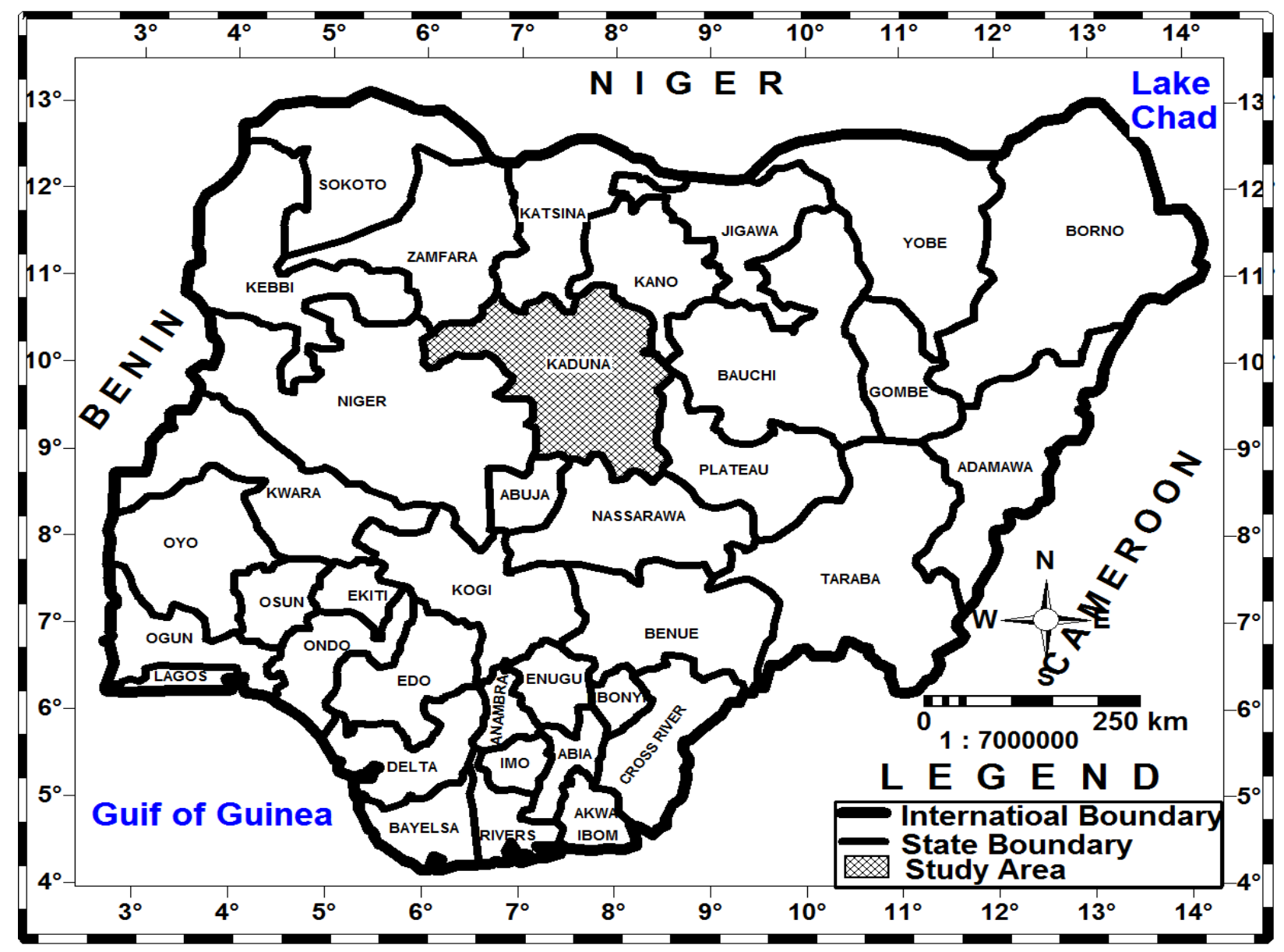

Figure 1. Kaduna State in the context of Nigeria

Source: Extracted from Google Map and drawn by the authors (2018) 


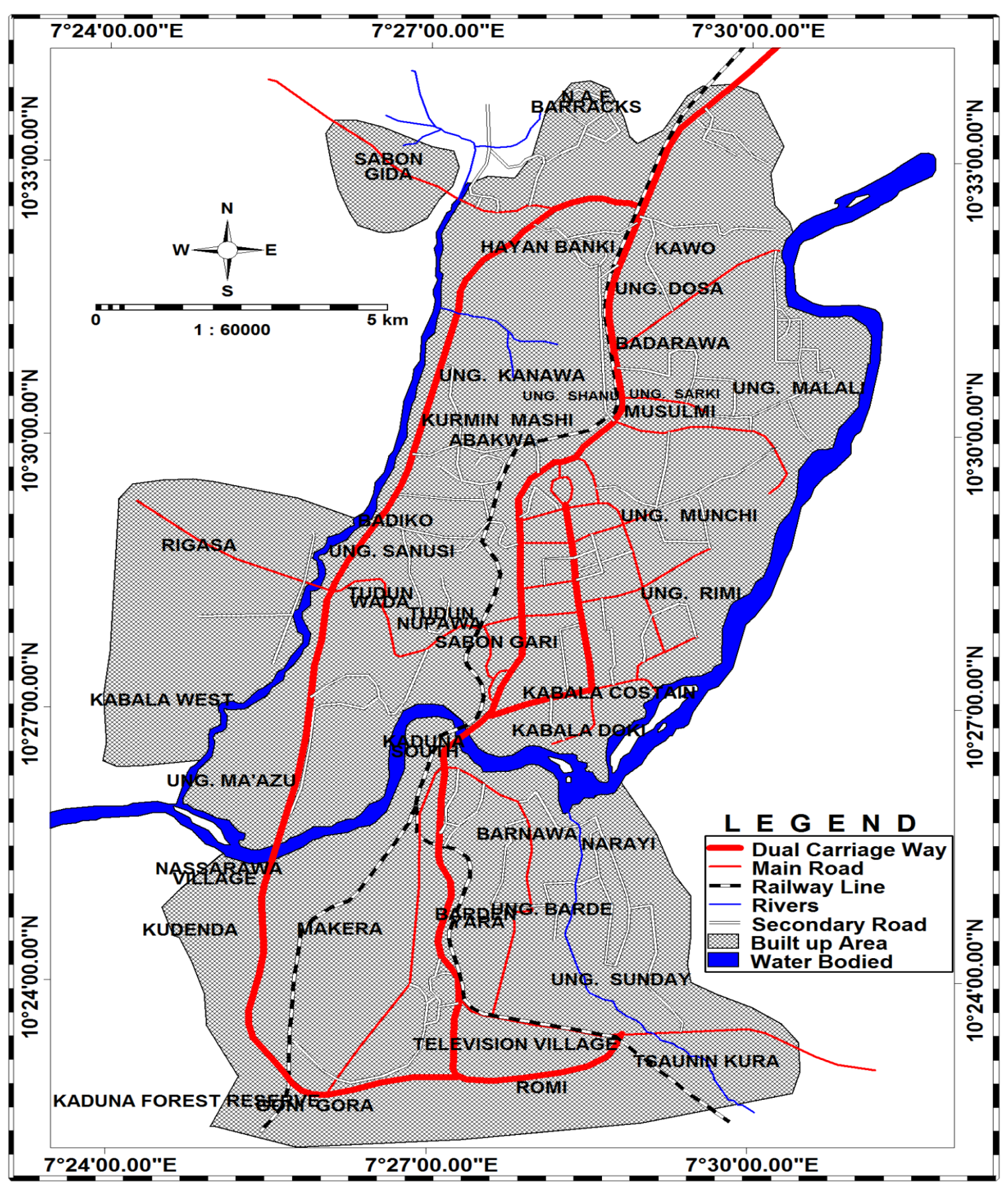

Figure 2. Roads networks in Kaduna metropolis

Source: Extracted from Google Map and drawn by the authors (2018)

\subsection{Research design}

A field survey was conducted to ascertain the locations used by FRSC in 2016, which was published in 2017. 71 bus stops were discovered, as reported by FRSC. FRSC is responsible for monitoring, managing, regulating and ensuring transport safety in Nigeria. Information collected during the visits includes; road traffic crashes data, enforcement agencies, spatiotemporal variation of accidents, and available facilities used at each location.

\subsection{Data sources}

2021 | Journal of Social, Humanity, and Education/ Vol 1 No 3, 209-226 
The data used in this study was mainly secondary, from a report obtained from FRSC (Kaduna State unit command, Kaduna, 2016). But the report contained accidents records from January 2016 to December 2016. Four visits to the locations were carried out each month from February 2017 to June 2018 to ascertain the authenticity of the data obtained from the FRSC Kaduna State command.

\subsection{Sample design and data acquisition}

FRSC used a total of 71 bus stops. One-third of the bus stop was systematically sampled and used in this study for authentication of the collected data from FRSC. Eight members of the research team went to the 24 bus stops each month rotationally. Each team member went with three field assistants to ascertain the feasibility of the areas being classified as hotspots by FRSC. This means that in each visit, four surveyors attended each of the 24 sampled bus stops. This also means each of the eight teams went eight times in two months within the stated period.

\subsection{Data analysis}

Descriptive method using table, percentage, chart and graph were used and inferential method using the Pearson's moment correlation using the raw score's method.

\section{Results and discussion}

\subsection{Road traffic accidents data in Kaduna metropolis}

Accident data of Kaduna metropolis was obtained primarily to ascertain the trend in a road traffic accident in the study area, to determine the spatiotemporal variations of road traffic accident, also to ascertain the number of accidents per week and month and also to identify the spatial variation of casualties and injuries in the study area and finally to ascertain the degree of association between accident and injuries/death.

Table 2. Reported cases of road traffic accident in Kaduna metropolis, 2017.

\begin{tabular}{|c|c|c|c|c|}
\hline ROUTE & LOCATION & DEATH & INJURY & $\begin{array}{l}\text { PEOPLE } \\
\text { INVOLVED }\end{array}$ \\
\hline \multirow[t]{11}{*}{ Township } & $\begin{array}{l}\text { Ahmadu Bello } \\
\text { Way }\end{array}$ & 0 & 3 & 3 \\
\hline & M/Buhari way & 2 & 5 & 7 \\
\hline & Enugu Road & 1 & 0 & 3 \\
\hline & $\begin{array}{l}\text { Nepa Round- } \\
\text { About }\end{array}$ & 0 & 2 & 5 \\
\hline & $\begin{array}{l}\text { Nnamdi } \\
\text { Azikiwe } \\
\text { express way }\end{array}$ & 2 & 4 & 18 \\
\hline & UTC Bus-stop & 3 & 5 & 10 \\
\hline & U/shanu & 1 & 0 & 4 \\
\hline & NDC & 0 & 3 & 5 \\
\hline & NDA bus stop & 0 & 6 & 11 \\
\hline & Mando garage & 1 & 2 & 4 \\
\hline & FRSC Gate & 2 & 2 & 4 \\
\hline
\end{tabular}




\begin{tabular}{|c|c|c|c|c|}
\hline & DICON & 0 & 2 & 2 \\
\hline \multirow{6}{*}{$\begin{array}{l}\text { Kaduna-Zaria } \\
\text { Express Way }\end{array}$} & Rigacikum & 3 & 50 & 91 \\
\hline & NTI & 1 & 8 & 17 \\
\hline & U/Kaji & 1 & 3 & 7 \\
\hline & $\begin{array}{l}\text { Tradefare } \\
\text { complex }\end{array}$ & 0 & 0 & 3 \\
\hline & Barakallahu & 1 & 4 & 4 \\
\hline & Kawo & 1 & 5 & 6 \\
\hline \multirow{4}{*}{$\begin{array}{l}\text { Kaduna-Abuja } \\
\text { Express Way }\end{array}$} & Abakwa & 1 & 5 & 10 \\
\hline & $\begin{array}{l}\text { Station } \\
\text { R/About }\end{array}$ & 0 & 1 & 2 \\
\hline & $\begin{array}{l}\text { Peugeout } \\
\text { Junction }\end{array}$ & 0 & 2 & 3 \\
\hline & Diamond Bank & 0 & 0 & 3 \\
\hline \multirow{2}{*}{$\begin{array}{l}\text { Kaduna-Birnin } \\
\text { Gwari Road }\end{array}$} & Mando & 1 & 17 & 22 \\
\hline & $\begin{array}{l}\text { NNPC Mega } \\
\text { Station }\end{array}$ & 2 & 2 & 4 \\
\hline TOTAL & & 23 & 131 & 245 \\
\hline
\end{tabular}

Source: (FRSC, 2016 confirmed by 2017-2018, field survey) 


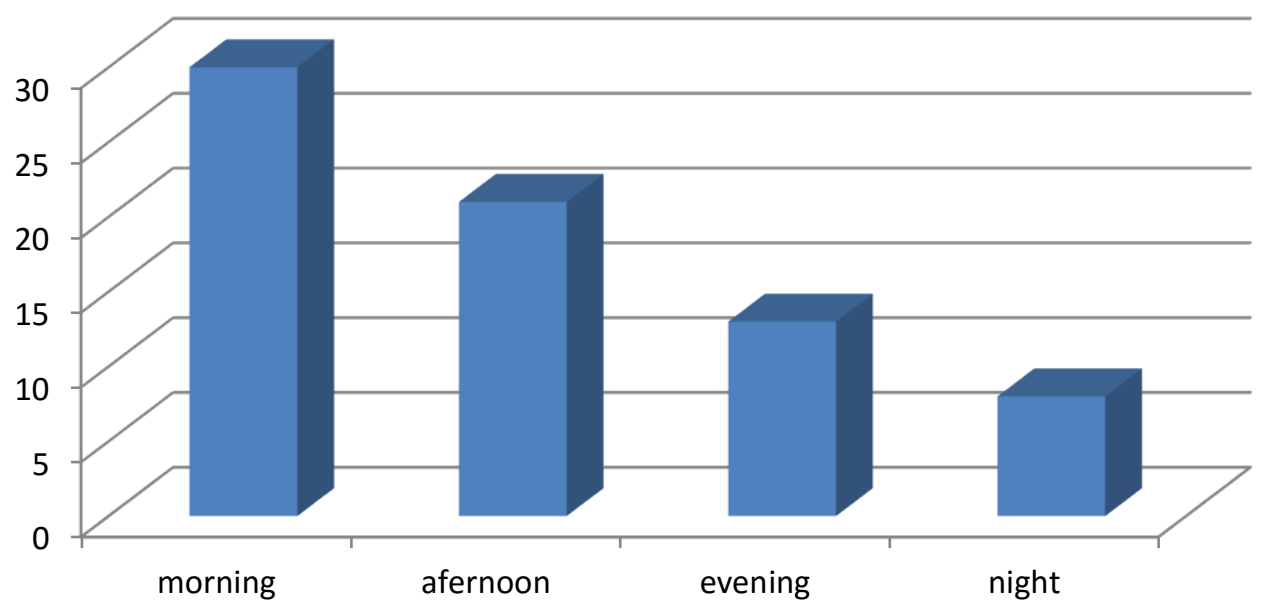

Figure 3. Commonest Period of Accidents

Source: (FRSC, 2016 confirmed by 2017-2018, field survey)

Figure 3 shows the temporal variation of a traffic accident in the study area. Morning time recorded the highest accident rate partially because it is a rush hour for workers, businessmen, students, etc. Nighttime recorded the lowest accident rate.

Table 3. Distribution of accidents by season

\begin{tabular}{lll}
\hline Period/Season & Frequency & Percent \% \\
\hline April-October (wet season) & 30 & 41.67 \\
November-March (dry season) & 42 & 58.33 \\
Total & $\mathbf{7 2}$ & $\mathbf{1 0 0}$ \\
\hline
\end{tabular}

(FRSC, 2016 confirmed by 2017-2018, field survey)

From table 3, the seasonal variation of vehicular traffic accidents and the dry season recorded more severe accidents than wet. This might be because road and vehicle users are more careful during the wet season.

The Pearson's moment correlation (r) was adopted using the raw score method to ascertain the degree of correlation between death and injuries in the study area.

Table 4. Pearson's Moment Correlation Analysis.

\begin{tabular}{llllll}
\hline $\mathrm{N}$ & $\mathrm{X}$ & $\mathrm{Y}$ & $\mathrm{XY}$ & $\mathrm{X}^{2}$ & $\mathrm{Y}^{2}$ \\
\hline 1 & 0 & 3 & 0 & 0 & 9 \\
2 & 2 & 5 & 10 & 4 & 25 \\
3 & 1 & 0 & 0 & 1 & 0 \\
4 & 0 & 2 & 0 & 0 & 4 \\
5 & 2 & 4 & 4 & 4 & 16 \\
6 & 3 & 5 & 15 & 9 & 25 \\
7 & 1 & 0 & 0 & 1 & 0
\end{tabular}




\begin{tabular}{|c|c|c|c|c|c|}
\hline 8 & 0 & 3 & 0 & 0 & 9 \\
\hline 9 & 0 & 6 & 0 & 0 & 36 \\
\hline 10 & 1 & 2 & 2 & 1 & 4 \\
\hline 11 & 2 & 2 & 4 & 4 & 4 \\
\hline 12 & 0 & 2 & 0 & 0 & 4 \\
\hline 13 & 3 & 50 & 150 & 9 & 2500 \\
\hline 14 & 1 & 8 & 8 & 1 & 64 \\
\hline 15 & 1 & 3 & 3 & 1 & 9 \\
\hline 16 & 0 & 0 & 0 & 0 & 0 \\
\hline 17 & 1 & 4 & 4 & 1 & 16 \\
\hline 18 & 1 & 5 & 5 & 1 & 25 \\
\hline 19 & 1 & 5 & 5 & 1 & 25 \\
\hline 20 & 0 & 1 & 0 & 0 & 1 \\
\hline 21 & 0 & 2 & 0 & 0 & 4 \\
\hline 22 & 0 & 0 & 0 & 0 & 0 \\
\hline 23 & 1 & 17 & 17 & 1 & 289 \\
\hline 24 & 2 & 2 & 4 & 4 & 4 \\
\hline Total & $\Sigma x=23$ & $\Sigma y=131$ & $\Sigma x y=235$ & $\Sigma x^{2}=43$ & $\Sigma y^{2}=3073$ \\
\hline
\end{tabular}

Where: $\mathrm{N}=$ Number of Accidents

$X=$ Deaths

$\mathrm{Y}=$ Injuries

$\Sigma=$ summation

Using the raw score formula $\frac{\Sigma N x y-(\Sigma x)(\Sigma y)}{\sqrt{\left(N \Sigma x^{2}\right)-\left(\Sigma x^{2}\right)(N \Sigma y 2-(\Sigma y 2)}}$

where $\Sigma N=24$

$$
\begin{aligned}
& \Sigma X=23 \\
& \Sigma Y=131 \\
& \Sigma X Y=235 \\
& \Sigma X^{2}=43 \\
& \Sigma Y^{2}=3073
\end{aligned}
$$

$$
\begin{array}{rlr}
\text { Raw score } & =\frac{(24 \times 235)-(23)-(131)}{\sqrt{24 \times 43}-(43) \times(24 \times 3073)-(3073)} & =\frac{5486}{\sqrt{989 \times 70679}} \\
& =\frac{(5640)-(23)-(131)}{\sqrt{(1032})-(43) \times(73752)-3073} & \\
& =\frac{5486}{\sqrt{69901531}} \\
& =\frac{5486}{8360.7} \\
& =0.7
\end{array}
$$

From table 4, it shows that there is high correlation of motality and road accident injuries as confirmed by r-value 0.7 . 
Table 5. The Contributory Causes of Road Traffic Accidents Reported in Kaduna metropolis, 2016.

\begin{tabular}{|c|c|c|}
\hline Causes & Frequency & Percentage $\%$ \\
\hline Speed violation & 18 & 25 \\
\hline Lost of control & 3 & 4.2 \\
\hline $\begin{array}{l}\text { Mechanically } \\
\text { vehicle }\end{array}$ & 0 & 0 \\
\hline Dangerous driving & 9 & 12.4 \\
\hline Sign light violation & 16 & 22.2 \\
\hline Wrongful overtaking & 4 & 5.6 \\
\hline Overloading & 0 & 0 \\
\hline Tyre burst & 2 & 2.8 \\
\hline Brake failure & 2 & 2.8 \\
\hline Bad road & 0 & 0 \\
\hline Dangerous overtaking & 4 & 5.6 \\
\hline Sleeping on steering & 0 & 0 \\
\hline Fatique & 0 & 0 \\
\hline Bad weather & 4 & 5.6 \\
\hline Use of phone while driving & 0 & 0 \\
\hline Others & 10 & 13.8 \\
\hline TOTAL & 72 & 100 \\
\hline
\end{tabular}

(FRSC, 2016 confirmed by 2017-2018, field survey)

Speed violation and sign light violation are the major causes of road accident fatalities in Kaduna metropolis. This accounts for the death of 6,6 people respectively. This was because, at high speed, the vehicle and the vehicle occupants are more exposed to an accident. The vehicle at high speed is very difficult to control. Thus, any misake or a short distraction can result in a fatal road accident. Dangerous driving had accounted for the death of 4 people, and dangerous overtaking resulted in the deaths of 2 people; loss of control, wrongful overtaking, and brake failure accounted for 1 person each (FRSC, 2016).

The outcome of this study corroborates (Jobin, 2015) where it was concluded that over-speeding was the major cause of accident along the Kaduna-Zaria highway. Another survey by FRSC (2015) showed that over-speeding account for $65 \%$ of road traffic accidents in Kaduna State.

\subsection{Vehicular involvement in road traffic accident}

From the definition of road traffic accident, vehicles were also factors contributing to a road traffic accident. They contribute immensely to road accident casualty and fatality in Kaduna metropolis. Other road users like pedestrians also contribute, but that of vehicles is more severe. Figure 4 showed vehicular involvement in a road traffic accident in Kaduna metropolis for the year 2016. 


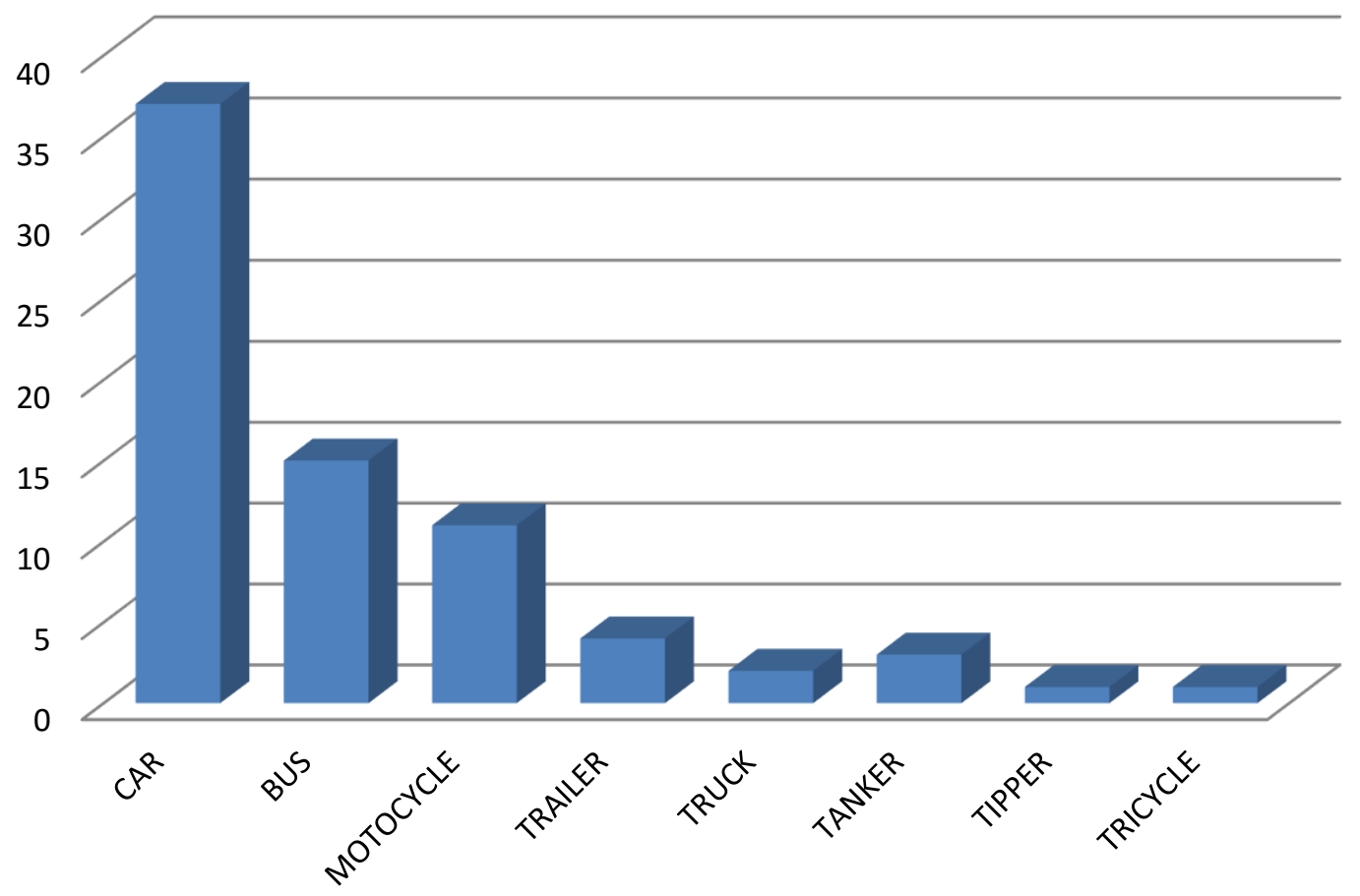

Figure 4. Vehicular Involvement in Road Traffic Accidents in Kaduna metropolis in 2016. (FRSC, 2016 confirmed by 2017-2018, field survey)

Cars were involved in 37 out of 72 road traffic accidents in Kaduna metropolis for the year 2016, which accounted for $51 \%$ of accident involvement. This may be due to the dense population of people in the working class, businessmen/women and commercial vehicle owners who operate primarily on cars in the metropolis. Buses account for $19.4 \%$ with a frequency of 14 accident involvement, motorcycles and tricycles account for 15.3 and 1.4\% each with frequencies; 11 and 1 respectively, a trailer was involved in 4 accidents truck, tanker and tipper were involved in 2,3 and 1 accidents respectively in road traffic accidents in 2016. There has been a rapid decrease in buses involvement in a road traffic accident over the years because of the decline in the number of buses operating in the state and the metropolis due to the increase in cheap and fuel economy commercial cars like; Gulf, Sharon, Peugeou 507, Opel Vectra, and much more.

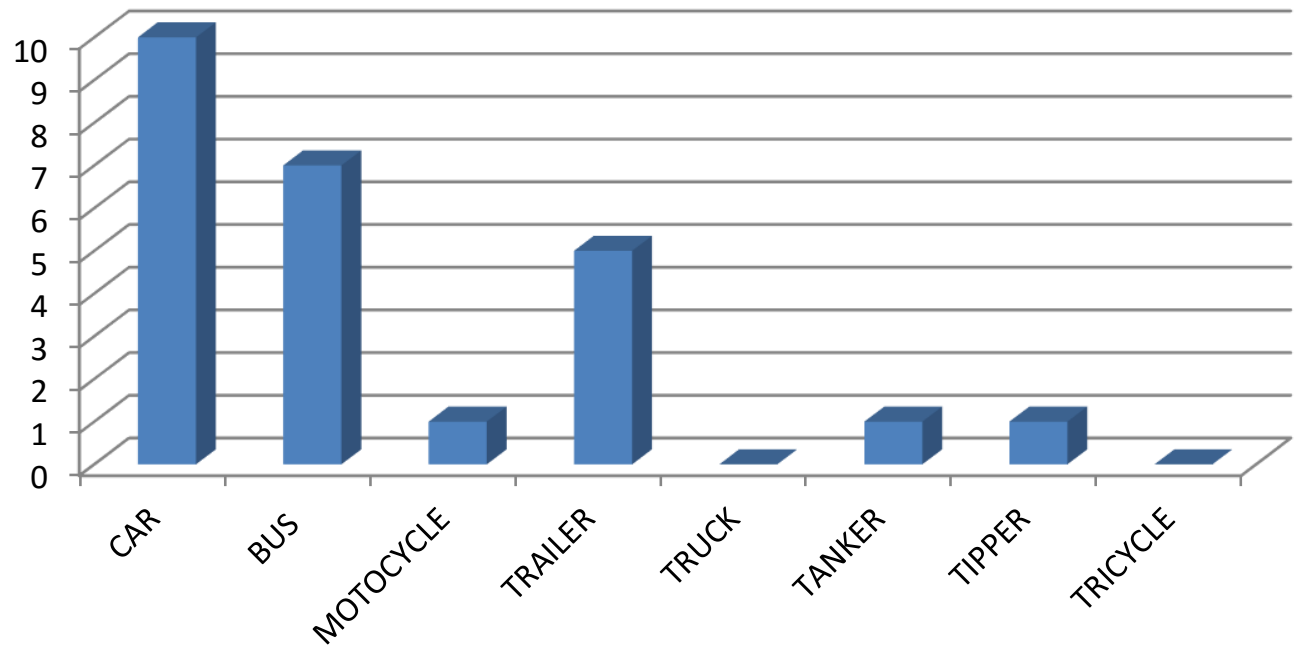

Figure 5. Vehicular Involvement in Road Traffic Fatalities in Kaduna metropolis in 2016 (FRSC, 2016 confirmed by 2017-2018, field survey) 
The vehicular involvement in a road traffic accident had accounted for the death of 72 people in the Kaduna metropolis. Because the users of cars are more compared to other vehicles in the metropolis, the car had the highest frequency of road traffic fatalities which accounts for the death of 10 people in Kaduna metropolis; buses account for the death of 7 people, trailer, truck and tipper accounts for the death of 4,1 and 1 people respectively.

The findings imply that more needs to be done to get accurate data to study this magnitude. Collaboration between geographers, transport planners and road safety agencies is required for the work requires adequate human resources, equipment and technology, among other resources.

\section{Conclusion}

The study reveals that accidents are the results of the combination of several factors and it is usually challenging to single out one main cause. Despite that, the findings indicate the combination of overspeeding or speed violation as the primary cause of road traffic accidents in Kaduna metropolis. The study also discovers that Rigachikun, Kawo, Nnamdi Azikiwe way (goodbye-pass), Ahmadu Bello way, and Ali Akilu Road are the most dangerous and prominent accident spots in Kaduna metropolis.

\section{Limitation}

One of the shortcomings of the study is that it was a report of FRSC analyzed by the authors, although a follow-up data collection was conducted and the findings revealed almost the same results. An updated data is required to give a more reliable result. Another limitation of the study took only four years from the day the report was released in 2017 to the time of publication of this study. However, the time was reduced to two years, given the 18 months taken from 2017-2018 to ascertain the report's authenticity. Additionally, the number of accidents might be more than what FRSC reported because they published only the accidents reported to them by the public or their staff members. Other accidents might have occurred but not reported. The follow-up data collection gives us the insight to hold this opinion.

There was also the application of the old method or hand method of Pearson's moment correlation analysis. Recent studies prefer using SPSS, but the authors felt that using the old method can still be helpful and exciting.

\section{Recommendations}

i) Installation of speed-reducing devices as a calming traffic measure should be developed to check or reduce the excesses of speed violation.

ii) Road infrastructure such as road signs, bridges, street lights, etc. should be adequately maintained, and if possible, be improved upon the existing ones along the roads in Kaduna metropolis. In addition, they should be provided where they lack along some of the studied roads; this will reduce speed violation, wrongful overtaking and dangerous overtaking.

iii) There is a need for regular vehicle inspection and patrols by the road safety corps to maintain or reduce the occurrence of road traffic accident in the study area for some vehicles in the study area were reported to have bad tyres need to be banned.

\section{References}

Agbonkhese, O., Yisa, G. L., Akanbi, L., and Daudu E. O. (2013). Road traffic accident in Nigeria: Causes and preventive measures. Civil and Environmental Research Journal. Ogun State, 3(13), $2-6$.

Astrom, J. S., Kent, M. P., and Jobin, R. D. (2006). Signatures for generations of road safety planning in Nairobi city, Kenya. Journal of eastern African Research and Development, 120, 186-201.

David, J.B. (2003). Over speeding accounts $65 \%$ of road traffic accidents in Plateau State. Plateau news online. Accessed from http://www.plateaunewsonline.wardpress.com/2015/07/24/

Deepthi, J.K. and Ganeshkumar, B. (2010) Identification of accident hot spot: a GIS Based implementation for Kannur District, Karala International Jornal of Geomatics and Geoscience. $1(1), 51-59$. 
Esbaugh, M. (2012). Putting the brakes on road traffic fatalities in Africa. African Features Brief Journal, 2(3), 1-6.

Federal Road Safety Commission (2015). Road traffic crashes data. Accessed from http://www.frsc.gov.ng/rtc.php, Retrieved on 13th March, 2017.

Federal Road Safety Corps (2015). Road traffic accident data. Retrieved from FRSC headquarters Kaduna.

Federal road safety corps (2016). Road traffic crashes data. Retrieved from FRSC headquarters Kaduna.

Haddon, W. (1969). The changing approach to the epidemiology, prevention, and amelioration of trauma: the transition to approaches etiologically rather than descriptively based. American Journal of Public Health and the Nations Health, 58(8), 1431-1438.

Jobin, P.D. (2015). Analysis of road traffic accident hotspots along Zaria-Kaduna expressway. Unpublished Phd Thesis, Department of Geography, Ahmadu Bello University, Zaria.

Kaduna State Government (2012). The state at a glance. Unpublished Handbook.

New Zealand Transport Agency (2013). High risk intersection guide. A publication on the road safety of New Zealand. 7-14.

Oduguru, M.O. (1992). Road traffic crashes kills $0.4 m$ of youths every year. An article on road traffic crashes in Nigeria. The Vanguard news paper April 4 p35. 1992.

Ohakwe J. Iwuese I.S and chikezie D.C (2011). Analysis of road traffic accident in Nigeria. A case study of Obinze/Nekede/Iheagwe Road in Imo State. Asian Journal of Applied Sciences, $4(2), 166-175$.

Onakomaiya, S.O. (1981). Trends in Nigerian road safety and accident situations, a paper presented at a conference on accident control, university of Lagos, 1989.

Salihu, H. A. (2009). Appraisal of road traffic crashes in Nigeria. Unpublished Phd Thesis, Department of Geography, Ahmadu Bello University, Zaria.

Sheriff, M. A. (2009). Traffic education and safety in Nigeria, Nitours Journal, 2(1), 5-15.

The Forum for Cities in Transition. (2016). www.google.com/city_ranking/kaduna. Retrieved 13 November 2016.

World Health Organization (2009). Global status report on road safety: Time for action, Geneva. Retrieved:http://www.who.int/violence_injury_prevention/road_safety_status/2009, Retrieved on 15 October, 2016.

World Health Organisation (2013). Road traffic injuries: fact sheet $N^{\circ} 358$. Retrieved on 13th March, 2017 http://www.who.int/mediacentre/factsheets/fs358/en/ 